\title{
Contribution of the Leukocyte Adherence Inhibition Test to the Evaluation of Cellular Immunoreactivity against Latex Extracts for Non-IgE-Mediated Latex- Fruit-Pollen Syndrome in Allergic Candidates to Exclusion Diets and Allergic Desensitization
}

\author{
Celso Eduardo Olivier, Daiana G. Pinto, Ana P. M. Teixeira, Jhéssica L. S. Santana, \\ Raquel A. P. G. Santos, and Regiane P. S. Lima
}

\section{ABSTRACT}

Background: Due to the lack of standardized laboratory procedures able to demonstrate specific non-IgE-mediated immune responses against latex allergens, these conditions are diagnosed mostly by clinical criteria based on empiric exclusion prescriptions monitored by in vivo challenge tests.

Objective: To evaluate the opportunity of an ex vivo challenge immunoassay, the Leukocyte Adherence Inhibition (LAI) Test (LAIT), to discriminate non-IgE-mediated latex-specific immunoreactivity.

Methods: Ex vivo challenge tests performed with Hevea Brasiliense's latex extract, monitored by LAIT, were assayed in an asymptomatic control group and a group of patients with diverse respiratory and cutaneous non-IgE-mediated allergic conditions, clinically diagnosed by a certified allergologist.

Results: The mean LAI of the control group was $8.3 \%$. The mean LAI of the complete patients' group was $41.1 \%$. The non-parametric WilcoxonMann-Whitney U (WMWU) test comparing the control group with the whole patient's group showed significance with a $p$-value $<0.00001$. The WMWU test comparing the control group with each other patient's group showed significance with a $p$-value $<\alpha=0.05$ for all comparisons. The WMWU test comparing the patients' groups between each other did not show any significant $p$-value.

Conclusion: Several patients from the diverse non-IgE-mediated allergic phenotypes presented variable immunoreactivity against the latex extract, as demonstrated by the LAIT, which proved to be an easy, quick, and inexpensive ex vivo immunoassay with the potential to predict individual immunoreactivity against Hevea brasiliensis latex allergens in real-world patients with non-IgE-mediated allergies.

Keywords: Allergic conjunctivitis, allergic rhinitis, asthma, atopic dermatitis, Hevea brasiliensis, hypersensitivity, latex, leukocyte adherence inhibition test, pharyngitis, urticaria.
Published Online: January 7, 2022

ISSN: $2736-5476$

DOI : 10.24018/ejclinicmed.2022.3.1.160

C. E. Olivier*

Instituto Alergoimuno de Americana, Brasil.

(e-mail: celso@alergoimuno.med.br)

D. G. Pinto

Instituto Alergoimuno de Americana, Brasil.

(e-mail: daianaguedes85@gmail.com) A. P. M. Teixeira

Instituto Alergoimuno de Americana, Brasil.g

(e-mail: monezzi88@gmail.com)

J. L. S. Santana

Instituto Alergoimuno de Americana, Brasil.

(e-mail: 1jhessica31@gmail.com)

R. A. P. G. Santos

Instituto Alergoimuno de Americana, Brasil.

(e-mail: raquel.cuidados@gmail.com)

R. P. S. Lima

Instituto Alergoimuno de Americana, Brasil.

(e-mail: regianepatussi@gmail.com)

*Corresponding Author

\section{INTRODUCTION}

The Hevea brasiliensis ( $H b)$, also known as rubber tree, is a member of the Euphorbiaceae family that possesses a great latex regenerative capacity allowing its renewable exploitation at an industrial scale [1]. Latex gloves have begun to be used at the beginning of the 1900s by medical surgeons, and until now, they are recognized by their nickname: "surgical gloves" [2]. Until the eighties, the use of latex gloves was not a strong habit among health professionals, being restricted to the operatory field. Little procedures were usually performed with bare hands. Until then, there were sparse reports of allergic reactions to latex [3]. Initially, the individuals that developed latex allergy usually were medical surgeons or patients submitted to multiple surgical procedures [4]. After the appearance of the HIV epidemic, there was an overspread use of disposable protective devices, turning the natural rubber allergy more common among other health workers, as well the appearance of latex allergy among condom users [5], [6]. After the improvement of the industrial techniques, and the implementation of controlled rubber tree cultivation areas around the world, the disposable latex gloves became more accessible, and their use become more common among non- 
health professionals, such as the hairdressers, the food handlers, and the children's caretakers, changing the profile of the latex-allergic individuals [7], [8]. The appearance of the COVID-19 pandemic has intensified the use of protective gloves, however, nowadays, there are several options to replace latex in the production of disposable gloves, such as vinyl or nitrile.

The $H b$ latex is the cytoplasm of the laticifers, specialized cells that produce a diversity of biopolymers of $\left(\mathrm{C}_{5} \mathrm{H}_{8}\right)_{n}$ isoprene units (natural rubber) to heal traumatic injuries against the tree [9]. Secreted with the natural rubber, there is a high variety of allergenic proteins and enzymes, that share common epitopes with other vegetal compounds [10]. The Allergen Nomenclature Sub-Committee of the World Health Association and the International Union of Immunological Societies cataloged, until now, 15 major groups of allergens from the $H b$ latex (Hev b 1 to 15) [11]. Several of these are pan-allergens, such as the Heveins (Hev b 6), the Patatin homolog (Hev b 7), the Profilins (Hev b 8), the Chitinases (Hev b 11), and the Lipid Transport Protein (LTP-Hev b 12), that share homologous epitopes with proteins of several fruits, tubers, and pollens [12], [13]. The cross-reactivity among latex allergens and proteins of pollens and several edible fruits and tubers began to be described by the nineties, originating the designation "latex-fruit-pollen syndrome" [14], [15]. Latex allergens may be responsible for IgEmediated, non-IgE-mediated, and mixed hypersensitivity reactions [13]. The great variety of allergens of the $H b$ latex and the diversity of hypersensitivity reactions and crossreactions turn the allergy to natural latex proteins into a complex immune condition requiring a multi-parametric approach [10]. The main strategy to treat these latex-fruitpollen syndromes is avoidance and sublingual desensitization, a practice first described in 1901 with natural pollens and nowadays with their allergoids [16]-[24]. The diagnosis of the Gell and Coombs' type I IgE-mediated hypersensitivity is a relatively easy task done with the help of allergic skin tests or immunoassays designed to detect latexspecific IgE. The type IV Gell and Coombs' cellular hypersensitivity reactions usually are diagnosed by in vivo challenge tests such as the contact tests [25]. To better comprehend the type II Gell and Coombs' non-IgEmediated hypersensitivity immune mechanisms around the latex hypersensitivity, we perform the Leukocyte Adherence Inhibition Test (LAIT) in outpatients with diverse non-IgEmediated allergic conditions. The main objective was to evaluate the possibility of unsuspected participation of latex hypersensitivity in the patients' symptoms that could suggest a further clinical investigation inside a management strategy, considering a diagnostic/therapeutic exclusion diet and/or the indication of allergen desensitization.

The Leukocyte Adherence Inhibition Test (LAIT) is an ex vivo challenge test designed by Halliday, in 1972, to evaluate the inhibitory effect of specific antigens on the glass adherence of leukocytes [26]-[31]. When not activated, leukocytes kept in live conditions possess the natural capacity to adhere to glass. When challenged by specific antigens to which they are sensitized, the leukocytes release paracrine soluble factors that interfere with glass adherence of nearby leukocytes, a nonspecific phenomenon, that can be quantified with a concomitant assay done with unchallenged plasma
[32]-[36]. Besides the leukocyte participation, the specific inhibition of the glass adherence also requires the engagement of specific antibodies, suggesting a type II Gell and Coombs antibody-dependent cellular-mediated immune response [37]-[40].

\section{Methods}

\section{A. Subjects}

After receiving Institutional Review Board approval, from the Instituto Alergoimuno de Americana (Brazil), a group of 456 patients (112 male; 18-90 years old; mean age $=49.1$ years, $\mathrm{SD}=16,7$ years) and a control group of 16 non-allergic subjects ( 4 male; $25-70$ years old; mean age $=47.8$ years, SD $=13,4$ years) were invited, with informed consent formularies, to voluntarily be submitted to allergy skin tests and provide blood samples to research specific IgE antibodies and to perform ex vivo challenge tests, according to the principles of Helsinki and the International Committee of Medical Journals Editors requirements of privacy [41]. The control did not present any allergic symptoms. All patients presented clinical signals and symptoms of allergic diseases, classified in groups, as described below. Patients and controlgroup individuals had non-detectable serum-specific IgE and non-reactive skin tests against latex extracts and at least 20 other diverse respiratory and food allergens [42]. The study was descriptive, retrospective, and did not interfere with the patient's treatment or the assistant physician's diagnosis. All relevant and mandatory laboratory health and safety measures have been complied with, within the complete course of the experiments.

\section{B. Clinical Groups}

\section{1) Intrinsic Atopic Dermatitis Group (iAD)}

Patients presenting exclusively signals and symptoms of intrinsic Atopic Dermatitis (iAD), without blood serum evidence of IgE-mediated hypersensitivity, and not showing other signs and/or respiratory or ocular symptoms were classified in the $\mathrm{iAD}$ group $(\mathrm{n}=134$; male $=34$; mean age $=$ 51.5 years; range: $18-87$ years; $\mathrm{SD}=18.1$ years)

\section{2) Intrinsic Allergic Rhinitis Group (iAR)}

Patients presenting purely with signals and symptoms of Allergic Rhinitis, without blood serum evidence of IgEmediated hypersensitivity, and not showing other signs and/or cutaneous or respiratory symptoms were classified in the intrinsic Allergic Rhinitis (iAR) group. The nickname "intrinsic" was just added to emphasize the fact that there was no evidence of systemic IgE mediation, similarly to what is already established concerning the $\mathrm{iAD}(\mathrm{n}=75$; male $=19$; mean age $=47$ years; range $18-85$ years, $\mathrm{SD}=17$ years).

\section{3) Intrinsic Ocular Allergy group (iOA)}

Patients referred by their ophthalmologists, with a clinical diagnosis of Ocular Allergy, without blood serum evidence of serum IgE-mediated hypersensitivity, and not showing other signs and/or cutaneous or respiratory symptoms were classified in the intrinsic Ocular Allergy (iOA) group. The nickname "intrinsic" was just added to emphasize the fact that there was no evidence of systemic IgE mediation, similarly to what is already established concerning the $\mathrm{iAD}(\mathrm{n}=16$; male 
$=5 ;$ mean age $=46.1$ years; range $=19-71$ years $; \mathrm{SD}=16.7$ years).

\section{4) Intrinsic Asthma group (iAS)}

Patients presenting signals and symptoms of Asthma, without evidence of blood serum IgE-mediated hypersensitivity, with or without symptoms of allergic rhinitis, and not showing other signs and/or cutaneous or ocular symptoms were classified in the intrinsic Asthma (iAS) group. The nickname "intrinsic" was just added to emphasize the fact that there was no evidence of systemic IgE mediation, similarly to what is already established concerning the $\mathrm{iAD}(\mathrm{n}=39$; male $=10$; mean age $=50.2$ years; range $=$ $18-80$ years; $\mathrm{SD}=15.6$ years).

\section{5) Intrinsic Atopic Dermatitis / Intrinsic Allergic Rhinitis} group (iAD/iAR)

Patients presenting conjoint signals and symptoms of Allergic Rhinitis and Atopic Dermatitis, without evidence of blood serum IgE-mediated hypersensitivity, and not showing other respiratory signs and/or ocular symptoms were classified in the $\mathrm{iAD} / \mathrm{iAR}$ group $(\mathrm{n}=36$; male $=5$; mean age $=46.1$ years; range $=18-82$ years; $\mathrm{SD}=16.2$ years $)$.

\section{6) Intrinsic Chronic Urticaria Group (iCU)}

Patients with persistent or recurrent urticaria for more than 2 months, with no evidence of IgE-mediated sensitization, were classified in the intrinsic Chronic Urticaria (iCU) group. The nickname "intrinsic" was just added to emphasize the fact that there was no evidence of systemic $\operatorname{IgE}$ mediation, similarly to what is already established concerning the iAD $(\mathrm{n}=103 ;$ male $=25 ;$ mean age $=47$ years; range $=18-99$ years; $\mathrm{SD}=16$ years).

\section{7) Intrinsic Chronic Pharyngitis (iCP)}

Most patients with Chronic Pharyngitis search the allergists due to concomitant symptoms of Allergic Rhinitis. The clinical sign defining this condition is the presence of hyperemic elevated plaques of reactive lymphoid tissue in the oropharynx [43]-[45]. They were classified in the intrinsic Chronic Pharyngitis (iCP) group with the nickname "intrinsic" just to emphasize the fact that there was no evidence of systemic IgE mediation, similarly to what is already established concerning the iAD. $(n=53$; male $=14$; mean age $=52.3$ years; range $18-83$ years; $S D=13$ years $)$.

\section{Latex extraction}

The Hevea brasiliensis centrifugated latex was bought from a local supplier (COLITEX - Poloni - São Paulo Brazil) in liquid form ( $60 \%$ latex: $1 \%$ ammonia). The latex was extracted in Coca's solution at $4{ }^{\circ} \mathrm{C}$ for 48 hours, before five steps of centrifugation and filtration for separation of the water-soluble fraction from solid particles [46]. The protein quantification of the allergen extracts was done according to Bradford's protein-dye binding methodology [47]. The $\mathrm{Hb}$ latex extract was diluted to a protein concentration of 1 $\mathrm{mg} / \mathrm{mL}$ and stored at $4{ }^{\circ} \mathrm{C}$. All relevant and mandatory laboratory health and safety measures have been complied with in the complete course of the experiments.

\section{Leukocyte Adherence Inhibition Test}

Plasma samples were collected in heparinized collection tubes. The ex vivo challenge tests were performed as described previously [48]. Shortly, each donor's fresh plasma was divided into two parts and used in paralleled ex vivo challenging tests with $H b$ latex extract and the unchallenged plasma assay. The plasma with high leukocyte content (buffy coat) was collected from the heparinized tube after one hour of sedimentation at $37{ }^{\circ} \mathrm{C}$ and aliquots of $100 \mu \mathrm{L}$ were distributed into Eppendorf tubes kept under agitation for 30 minutes $\left(200 \mathrm{rpm}\right.$ at $37^{\circ} \mathrm{C}$ ) with (or without, as used as control) antigen extract $(10 \mu \mathrm{L}$ of a solution with $1 \mathrm{mg} / \mathrm{mL}$ and $\mathrm{pH}$ 7.5). After incubation, the plasma was allocated into a standard Neubauer hemocytometer counting chamber with a plain, non-metallic glass surface and left to stand for 2 hours at $37^{\circ} \mathrm{C}$ in the humidified atmosphere of the covered water bath to allow leukocytes to adhere to the glass. Next, leukocytes were counted, the coverslip was removed, and the chamber was washed by immersion in a beaker with PBS at $37{ }^{\circ} \mathrm{C}$. A drop of PBS was added to the hemocytometer chamber and a clean coverslip was placed over it. The remaining cells were counted in the same squares as previously examined. The percentage of Leukocyte Adherence (LA) of each assay was estimated as: (the number of leukocytes observed on the hemocytometry chamber after washing divided by the number of leukocytes observed on the hemocytometry chamber before washing) and multiplied by 100 (\%). The Leukocyte Adherence Ratio (LAR) was estimated based on the ratio between the LA from the antigen-specific challenged groups and the LA from the unchallenged control group: LAR $=$ LA of the challenged sample divided by LA of unchallenged control sample; multiplied by $100(\%)$. To further calculate the Leukocyte Adherence Inhibition (LAI) the LAR was subtracted from $100(\%)$.

\section{E. Graphic Presentation of Data and Statistics}

A column graph was plotted with the mean LAIT results of each group (Fig. 1). Cascade graphs were assembled according to the distribution of the tests among the range of results of each group (Fig. 2 to 9). The data of the patients' groups were compared with the control group by the nonparametric Wilcoxon-Mann-Whitney U test (Table I) [49], [50].

\section{RESULTS}

TABLE I: NON-PARAMETRIC WILCOXON-MANN-WHITNEY U TEST (WMWUT) COMPARING THE CONTROL GROUP WITH EACH OTHER PATIENT'S GROUP

\begin{tabular}{ccccc}
\hline \hline Group & Group & $\mathrm{U}$ & $z$-score & $p$-value \\
\hline \hline Control & Patients & $1,421.5$ & 415.09 & $<0.00001$ \\
Control & iAR & 286.5 & 3.30 & 0.00104 \\
Control & iAS & 133 & 330.78 & 0.00094 \\
Control & iCP & 192.5 & 3.30 & 0.00104 \\
Control & iCU & 261 & 4.38 & $<0.00001$ \\
Control & iAD/iAR & 109 & 3.53 & 0.0004 \\
Control & iAD & 400 & 4.08 & $<0.00001$ \\
Control & iOA & 39.5 & $(-) 3.31$ & 0.0009 \\
\hline \hline
\end{tabular}

The mean LAI of the control group was $8.3 \%$ (range $=0-$ $53 \%$; SD $=14.7 \%$ ). The mean LAI of the complete patients' group was $41.1 \%$ (range $=0-100 \%$; $\mathrm{SD}=31.3 \%)$. The mean LAI of the iAR group was $35.9 \%$ (range $=0-100 \%$; $\mathrm{SD}=$ $31.2 \%$ ). The mean LAI of the iAS group was $38.1 \%$ (range $=$ $0-94 \%$; SD $=30.8 \%$ ). The mean LAI of the iCP group was 
$38.2 \%($ range $=0-99 \% ; \mathrm{SD}=31.6 \%)$. The mean LAI of the iCU group was $42.3 \%$ (range $=0-100 \%$; $\mathrm{SD}=28.9 \%)$. The mean LAI of the $\mathrm{iAD} / \mathrm{iAR}$ group was $42.9 \%$ (range $=0-$ $100 \%$; $\mathrm{SD}=32 \%$ ). The mean LAI of the $\mathrm{iAD}$ group was $44 \%$ (range $=0-100 \% ; \mathrm{SD}=32.6 \%$ ). The mean LAI of the $\mathrm{iOA}$ group was $46.9 \%$ (range $=0-88 \%$; $\mathrm{SD}=29.3$ The nonparametric Wilcoxon-Mann-Whitney U (WMWU) test comparing the control group with the whole patient's group showed significance with a $p$-value $<0.00001$. The WMWU test comparing the control group with each patient's group showed significance with a $p$-value $<\alpha=0.05$ for all comparisons. The non-parametric Wilcoxon-Mann-Whitney U test comparing the patients' groups between each other did not show any significant $p$-value $<\alpha=0.05$. The cascade graphs visually showed that most subjects of the control group did not present significative immunoreactivity against the latex extract, while there was a heterogeneous distribution of results inside each patients group, demonstrating that several patients from the diverse allergic phenotypes groups presented a significative immunoreactivity against the latex extract, as demonstrated by the TIAL.

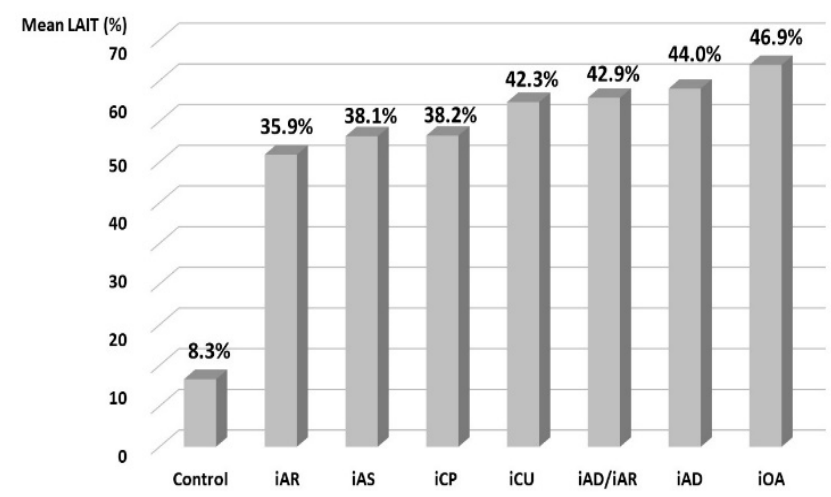

Fig. 1. Column comparison chart with the average Leukocyte Inhibition (\%) of the ex vivo challenge tests performed with Hevea brasiliensis latex extract, monitored by Leukocyte Adherence Inhibition Tests, grouped according to the control group and clinical symptoms of patients' groups.

iAR: intrinsic Allergic Rhinitis; iAS: intrinsic Asthma; iCP: intrinsic

Chronic Pharyngitis; iCU: intrinsic Chronic Urticaria; iAD/iAR: combined intrinsic Atopic Dermatitis and intrinsic Allergic Rhinitis; iAD: intrinsic Atopic Dermatitis; iOA: intrinsic Ocular Allergy.

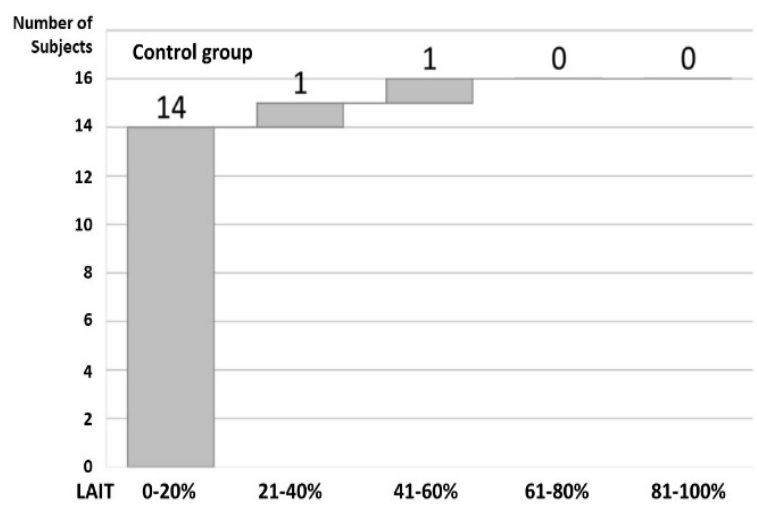

Fig. 2. Cascade distribution chart of the number of ex vivo challenge tests performed with Hevea brasiliensis latex extract monitored by Leukocyte

Adherence Inhibition Tests, according to the range of results (\%) of Leukocyte Adherence Inhibition (LAI) of 16 control subjects, presenting no allergic-related symptoms.

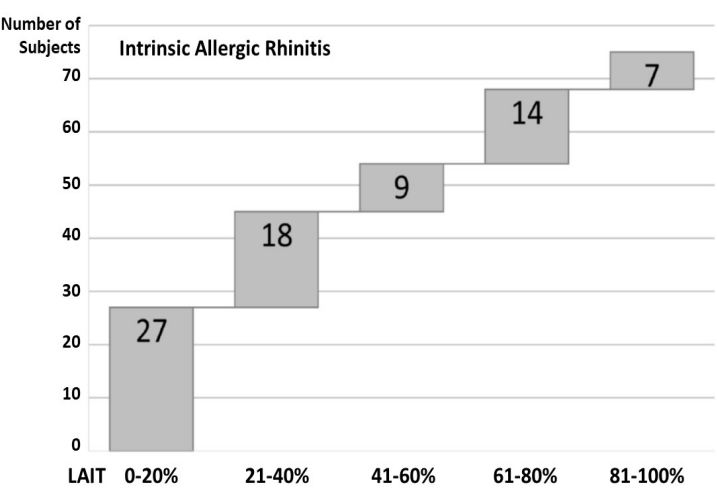

Fig. 3. Cascade distribution chart of the number of ex vivo challenge tests performed with Hevea brasiliensis latex extract monitored by Leukocyte Adherence Inhibition Tests, according to the range of results (\%) of Leukocyte Adherence Inhibition (LAI) of 75 patients with non-IgEmediated intrinsic Allergic Rhinitis (iAR).

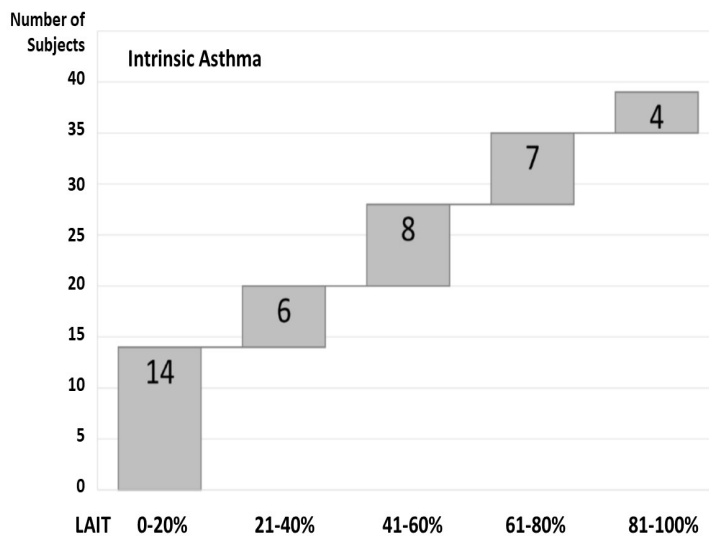

Fig. 4. Cascade distribution chart of the number of ex vivo challenge tests performed with Hevea brasiliensis latex extract monitored by Leukocyte Adherence Inhibition Tests, according to the range of results (\%) of Leukocyte Adherence Inhibition (LAI) of 39 patients with non-IgEmediated intrinsic Asthma (iAS).

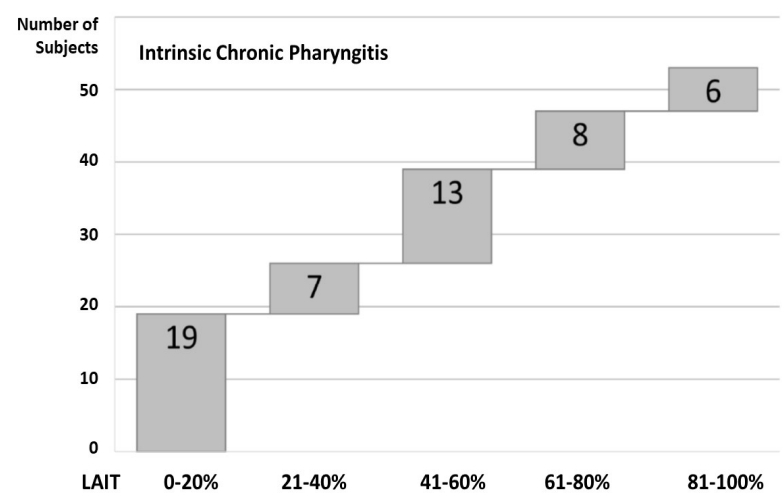

Fig. 5. Cascade distribution chart of the number of ex vivo challenge tests performed with Hevea brasiliensis latex extract monitored by Leukocyte Adherence Inhibition Tests, according to the range of results (\%) of Leukocyte Adherence Inhibition (LAI) of 53 patients with non-IgEmediated intrinsic Chronic Pharyngitis (iCP). 


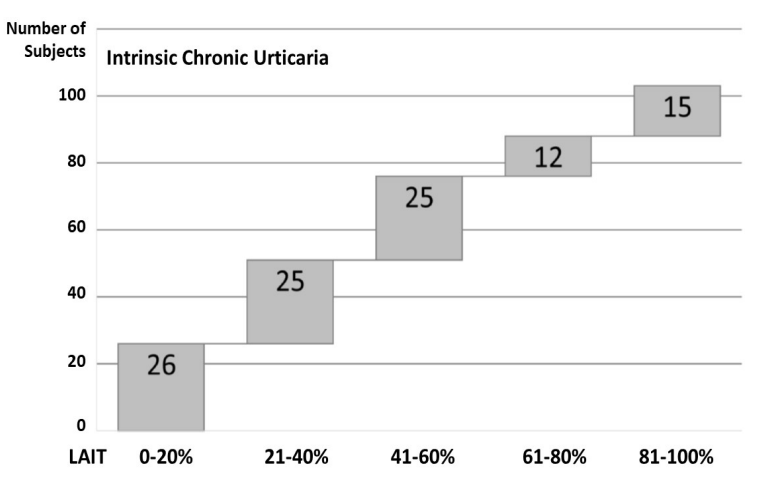

Fig. 6. Cascade distribution chart of the number of ex vivo challenge tests performed with Hevea brasiliensis latex extract monitored by Leukocyte Adherence Inhibition Tests, according to the range of results (\%) of

Leukocyte Adherence Inhibition (LAI) of 103 patients with non-IgEmediated intrinsic Chronic Urticaria (iCU).

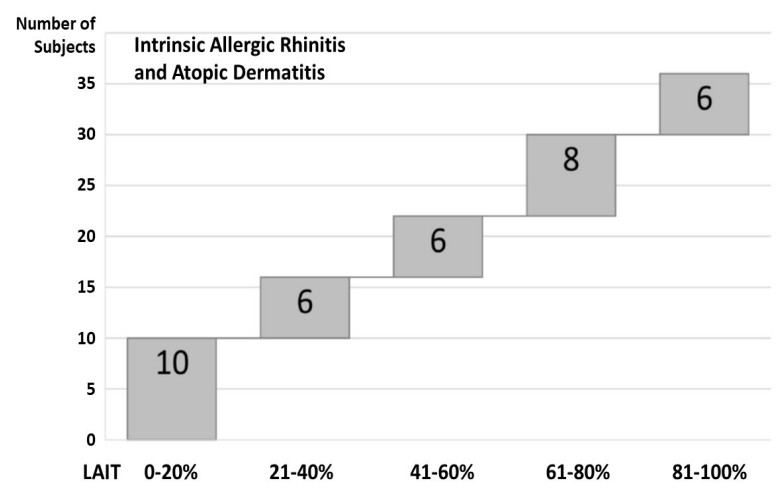

Fig. 7. Cascade distribution chart of the number of ex vivo challenge tests performed with Hevea brasiliensis latex extract monitored by Leukocyte Adherence Inhibition Tests, according to the range of results (\%) of Leukocyte Adherence Inhibition (LAI) of 36 patients with non-IgEmediated combined intrinsic Atopic Dermatitis and intrinsic Allergic Rhinitis (iAD/iAR).

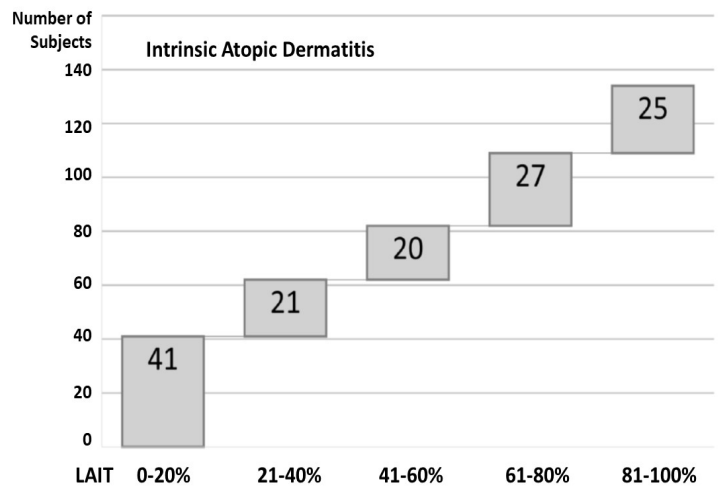

Fig. 8. Cascade distribution chart of the number of ex vivo challenge tests performed with Hevea brasiliensis latex extract monitored by Leukocyte

Adherence Inhibition Tests, according to the range of results (\%) of

Leukocyte Adherence Inhibition (LAI) of 134 patients with non-IgEmediated intrinsic Atopic Dermatitis (iAD).

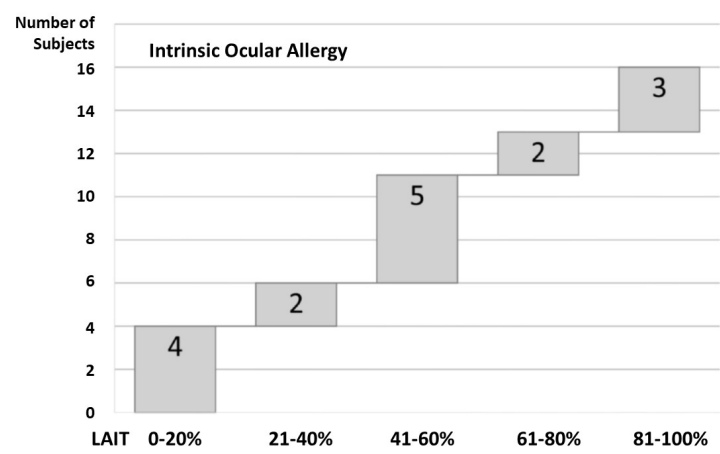

Fig. 9. Cascade distribution chart of the number of ex vivo challenge tests performed with Hevea brasiliensis latex extract monitored by Leukocyte Adherence Inhibition Tests, according to the range of results (\%) of Leukocyte Adherence Inhibition (LAI) of 16 patients with non-IgEmediated intrinsic Ocular Allergy (iOA).

\section{Discussion}

When classifying the diverse kinds of hypersensitivity reactions, Gell and Coombs described three distinct nonIgE-mediated groups of immune mechanisms that could produce clinically significant syndromes. The Gell and Coombs classification is rather a broader vision of four groups of immune interactions, according to the main participants of the sequential chain of events producing the disease. However, the immune system is not so simplistically compartmentalized, and the existence of one mechanism of hypersensitivity does not exclude the others. The complex immune interactions, as we know nowadays, speak more in favor that rather than a single mechanism producing allergic disease, there are instead "mixed" mechanisms participating in the physiopathology. When searching for a culprit for an allergic symptom, the physicians usually stop the search when it is found an IgE-mediated hypersensitivity, however, the patient may also be under the influence of uncovered non-IgE-mediated hypersensitivities. The discrepancy between two groups of patients with absolutely the same clinical presentation and different $\operatorname{IgE}$ profiles, gives rise to the concept of "extrinsic" and "intrinsic" allergy, as a reference to two phenotypes of patients according to the evidence (or not) of IgE-mediated hypersensitivity [51]-[54]. The significant difference between the mean LAI of the control group and the patients' groups demonstrated that the ex vivo challenge test performed with the $H b$ latex extract, monitored by the LAIT, can differentiate the specific immunoreactivity between the groups. The largest LAI found in the control group was $53 \%$, which is possibly due to an asymptomatic sensitization since most ex vivo challenge tests from the control group resulted in the LAI $=0 \%$. This fact also states that the finding of immunoreactivity against an allergen as demonstrated by the LAIT does not mean necessarily the existence of an allergic disease. Anyway, the link between the immunoreactivity demonstrated by the LAIT and the effective participation of the allergen in the pathophysiology of each allergic patient may only be determined by a careful in vivo challenge test initiated with an exclusion diet and a controlled re-introduction of the allergen through an Oral Challenge Test. The lack of clinically available immunoassays to predict the non- $-\mathrm{IgE}-$ mediated hypersensitivities turns, literally, the diagnosis of these conditions, a challenge to most physicians. The in vivo 
challenge tests are laborious, costly, time-wasting, and depend on a previous successful exclusion diet to allow the resurgence of the allergic symptoms. The feasibility of an ex vivo challenge test able to select a group of antigens to proceed with the exclusion diet and the further in vivo oral challenges tests is a highly desirable tool. The inhibition of the leukocytes' glass adherence is an indicator of the existence of a specific immunoreactivity against a given antigen. It does not diagnosis a clinical disease but may point out some suspects to be appreciated by the judgmental clinical eye. The LAIT may be used as a triage test that just indicates the release of cytokines after the encounter with a specific antigen.[55] The LAIT is a feasible test, easily adaptable to the routine of a medical facility dedicated to the diagnosis and/or the treatment of allergic patients. In our series, several patients from the diverse non-IgE-mediated allergic phenotype presented variable immunoreactivity against the $H b$ latex extract, as demonstrated by the LAIT, which proved to be an easy, quick, and inexpensive ex vivo immunoassay with the potential to predict individual immunoreactivity against latex allergens in real-world patients with non-IgE-mediated allergies.

\section{ABBREVIATIONS}

\section{$H b$ : Hevea brasiliensis}

iAR: intrinsic Allergic Rhinitis

iAS: intrinsic Asthma

iAD: intrinsic Atopic Dermatitis

iCP: intrinsic Chronic Pharyngitis

iCU: intrinsic Chronic Urticaria

iOA: intrinsic Ocular Allergy

LA: Leukocyte Adherence

LAR: Leukocyte Adherence Ratio

LAI: Leukocyte Adherence Inhibition

LAIT: Leukocyte Adherence Inhibition Test

WMWU test: Wilcoxon-Mann-Whitney U test

\section{REFERENCES}

[1] Chen X, Deng Z, Yu D, Zhang X, An Z, Wu W, et al. Genome-Wide Identification and Analysis of Small Nucleolar RNAs and Their Roles in Regulating Latex Regeneration in the Rubber Tree (Hevea brasiliensis). Frontiers in Plant Science. 2021;12: 731484-731484.

[2] Ownby DR. A history of latex allergy. J Allergy Clin Immunol. 2002; 110: 125336.

[3] Nutter AF. Contact urticaria to rubber. British Journal of Dermatology. 1979; 101: 597-598.

[4] Filon FL, Radman G. Latex allergy: a follow up study of 1040 healthcare workers. Occup Environ Med. 2006; 63: 121-125.

[5] Lopes RA, Benatti MC, Zollner R. A review of latex sensitivity related to the use of latex gloves in hospitals. Aorn J. 2004; 80: 64-71.

[6] Espin M, Didier A, Perez T, Carre P, Leophonte P. Anaphylactic manifestations during protected sexual intercourse disclosing allergy to latex. Rev Med Interne. 1991; 12: 447-448.

[7] Kawai M, Kondo Y, Nakajima Y, Tsuge I, Yoshikawa T, Yagami A, et al. Akasawa, Changes in the characteristics of patients with latex allergy from 1999 to 2014. Fujita Medical Journal. 2020; 6: 67-72.

[8] Lokman U, Akoğlu A. Food allergy knowledge, attitudes, and practices of food handlers working in the five-star hotel kitchens in Turkey. Food Health. 2002; 8: 23-34.

[9] Sant'Anna IC, Gouvêa LRL, Martins MA, Scaloppi Junior EJ, de Freitas RS, Gonçalves PS. Genetic diversity associated with natural rubber quality in elite genotypes of the rubber tree. Sci Rep. 2021; 11: 020-80110.

[10] Nucera E, Rizzi A, Buonomo A, De Pasquale T, Pecora V, Colagiovanni A, et al. The clinical meaning of positive latex SIgE in patients with food/pollen adverse reactions. Int $J$ Immunopathol Pharmacol. 2012; 25: 445-453.
[11] Sub-Committee AN. The official list of allergens. WHO/International Union of Immunological Societies. 2021.

[12] Rodriguez-Del-Río P, Díaz-Perales A, Sánchez-García S, Escudero C, Ibáñez MD, Méndez-Brea P, et al. Profilin, a Change in the Paradigm. J Investig Allergol Clin Immunol. 2018; 28: 1-12.

[13] Parisi CAS, Kelly KJ, Ansotegui IJ, Gonzalez-Díaz SN, Bilò MB, Cardona V, et al. Update on latex allergy: New insights into an old problem. World Allergy Organization Journal. 2021; 14: 100569.

[14] Mäkinen-Kiljunen S. Banana allergy in patients with immediate-type hypersensitivity to natural rubber latex: characterization of crossreacting antibodies and allergens. J Allergy Clin Immunol. 1994;93: 990-996.

[15] Blanco C, Carrillo T, Castillo R, Quiralte J, Cuevas M, Latex allergy: clinical features and cross-reactivity with fruits. Ann Allergy. 1994;73: 309-314.

[16] Curtis H. The immunization treatment of hay fever. JAMA. 1902; 39: 1267-1268.

[17] Kinaciyan T, Jahn-Schmid B, Radakovics A, Zwolfer B, Schreiber C, Francis JN, et al. Successful sublingual immunotherapy with birch pollen has limited effects on concomitant food allergy to apple and the immune response to the Bet v 1 homolog Mal d 1. J Allergy Clin Immunol. 2007; 119: 937-943.

[18] Nucera E, Schiavino D, Sabato V, Colagiovanni A, Pecora V, Rizzi A, et al. Sublingual immunotherapy for latex allergy: tolerability and safety profile of rush build-up phase. Curr Med Res Opin. 2008; 24: $1147-1154$.

[19] Nucera E, Schiavino D, Pollastrini E, Rendeli C, Pietrini D, Tabacco F, et al. Sublingual desensitization in children with congenital malformations and latex allergy. Pediatr Allergy Immunol. 2006; 17: 606-612.

[20] Nolte H, Waserman S, Ellis AK, Biedermann T, Würtzen PA. Treatment Effect of the Tree Pollen SLIT-Tablet on Allergic Rhinoconjunctivitis During Oak Pollen Season. J Allergy Clin Immunol Pract. 2021; 9: 1871-1878.

[21] Olivier CE, Lima RPS, Argentão DGP, Silva MDd, Santos RAPG, Pensuti M, et al. Group-specific Multi-allergen Sublingual/Swallow Immunotherapy Improves the Quality of Life of Polysensitized Children and Adults with Allergic Rhinitis. Journal of Allergy \& Therapy. 2013; 4: 148.

[22] D'Anneo RW, Arena A, Gammeri E, Bruno ME, Falagiani P, Riva G, et al. Parietaria sublingual allergoid immunotherapy with a co-seasonal treatment schedule. Allergologia et Immunopathologia. 2008; 45: 7984.

[23] Ariano R, Kroon AM, Augeri G, Canonica GW, Passalacqua G. Longterm treatment with allergoid immunotherapy with Parietaria. Clinical and immunologic effects in a randomized, controlled trial. Allergy. 1999;54: 313-319.

[24] Olivier CE. The use of allergoids and adjuvants in Allergen Immunotherapy. Arch Asthma Allergy Immunol. 2017; 1: 40-60.

[25] Hamilton RG. Diagnosis of natural rubber latex allergy. Methods. 2002; 27: 22-31.

[26] Halliday WJ, Miller S. Leukocyte adherence inhibition: a simple test for cell-mediated tumour immunity and serum blocking factors. Int $J$ Cancer. 1972; 9: 477-483.

[27] Bullen AW, Losowsky MS. Comparison of a leucocyte adherence test with the leucocyte migration inhibition test and skin reactivity to PPD. Clin Exp Immunol. 1978; 31: 408-413.

[28] Kuratsuji T. Studies on leukocyte adherence inhibition test. Part II. Clinical applications of LAI test to detect delayed type hypersensitivity in infants and children. Keio J Med. 1981; 30: 65-69.

[29] Kuratsuji T. Studies on leukocyte adherence inhibition test. Part I. Studies on mechanisms of leukocyte adherence inhibition. Keio J Med. 1981; 30: 53-63.

[30] Olivier CE, Lima RPS, Pinto DG, Santos RAPG, Silva GKM, Lorena SLS, et al. In search of a tolerance-induction strategy for cow's milk allergies: significant reduction of beta-lactoglobulin allergenicity via transglutaminase/cysteine polymerization. Clinics. 2012; 67: 11711179 .

[31] Thomson DMP. Assessment of immune status by the leukocyte adherence inhibition test. Academic Press, New York. 1982.

[32] Halliday WJ. Historical Background and Aspects of the Mechanism of Leukocyte Adherence Inhibition. Cancer Res. 1979; 39: 558-563.

[33] Appelboom T, Famaey JP, Gortz R, Wybran J. Effect of levamisole on leukocyte adherence inhibition. Agents Actions. 1981; 11: 604-605.

[34] Fink A, Bibi H, Eliraz A, Tabachnik E, Bentwic Z. Leukotrienes (LTC4, LTD4) confer glass non-adherence on leukocytes of asthmatic individuals. Dependency on cyclooxygenase products and calcium ion. Immunol Lett. 1985; 10: 319-323.

[35] Fink A, Shahin R, Eliraz A, Bibi H, Berkenstadt H, Levin S, et al. Interferon modulates the leukotriene $\mathrm{C} 4$-induced non-adherence 
properties of leukocytes: acquisition of an asthmatic phenotype. Immunol Lett. 1985; 10: 159-163.

[36] Iwabuchi K, Yamashita T. Platelet-derived neutrophil adherenceinhibiting factor in humans. Blood. 1990; 76: 2368-2373.

[37] Powell AE, Birch RE, Murrell H, Sloss AM. Cell populations in leucocyte adherence inhibition: requirement for $\mathrm{T}$ lymphocytes with IgG Fc receptors. Immunology. 1982; 46: 689-696.

[38] Olivier CE, Lima RPdS, Pinto DG, Santos RAPGd. The Plasma Preincubation with Papain Before the Assay Suggests that a Gell and Coombs Type II Reaction is Been Demonstrated by the Leukocyte Adherence Inhibition Test. Biomedical Journal of Scientific \& Technical Research. 2021; 36: 28647 - 28655.

[39] Kotlar HK, Sanner T. Role of circulating antibodies in the humoral leukocyte adherence inhibition response of lung and breast cancer patients. Cancer Lett. 1980; 11: 11-19.

[40] Gell PGH, Coombs RRA. Classification of Allergic Reactions Responsible for Clinical Hypersensitivity and Disease. Clinical Aspects of Immunology, Blackwell Scientific Publications, Oxford, $1968 ; 575-596$.

[41] World Medical Association Declaration of Helsinki: ethical principles for medical research involving human subjects. JAMA. 2013; 310 2191-2194.

[42] Olivier CE, Argentão DGP, Santos RAPG, Silva MD, Lima RPS, Zollner RL. Skin scrape test: an inexpensive and painless skin test for recognition of immediate hypersensitivity in children and adults. The Open Allergy Journal. 2013; 6: 9-17.

[43] Stephenson KN. Acute and chronic pharyngitis across the lifespan. Lippincotts Prim Care Pract. 2000; 4: 471-489.

[44] Li Z, Huang J, Hu Z. Screening and Diagnosis of Chronic Pharyngitis Based on Deep Learning. Int J Environ Res Public Health. 2019; 16.

[45] Hollender AR. Hypertrophy of the lingual tonsil and lymphoid tissue of the pharynx; Reduction by electro-coagulation. The Laryngoscope. 1932; 42: 622-626.

[46] Coca AF. Studies in Specific Hypersensitiveness V. The Preparation of Fluid Extracts and Solutions for Use in the Diagnosis and Treatment of the Allergies with Notes on the Collection of Pollens. The Journal of Immunology. 1922; 7: 163-178.

[47] Bradford MM. A rapid and sensitive method for the quantitation of microgram quantities of protein utilizing the principle of protein-dye binding. Anal Biochem. 1976; 72: 248-254.

[48] Olivier CE, Pinto DG, Lima RPS, Silva MDd, Santos RAPG, Teixeira APM, et al. Assessment of Immunoreactivity against Therapeutic Options Employing the Leukocyte Adherence Inhibition Test as a Tool for Precision Medicine. European Journal of Clinical Medicine. 2021; 2: $40-45$.

[49] Kim H-Y. Statistical notes for clinical researchers: Nonparametric statistical methods: 1. Nonparametric methods for comparing two groups. Restorative Dentistry \& Endodontics. 2014; 39: 235-239.

[50] Fay MP, Proschan MA. Wilcoxon-Mann-Whitney or t-test? On assumptions for hypothesis tests and multiple interpretations of decision rules. Stat Surv. 2010; 4: 1-39.

[51] Kerschenlohr K, Decard S, Darsow U, Ollert M, Wollenberg A. Clinical and immunologic reactivity to aeroallergens in "intrinsic" atopic dermatitis patients. J Allergy Clin Immunol. 2003; 111(1): 1957.

[52] Karimkhani C, Silverberg JI, Dellavalle RP. Defining intrinsic vs. extrinsic atopic dermatitis. Dermatol Online J. 2015; 21

[53] Tokura Y. Extrinsic and intrinsic types of atopic dermatitis. J Dermatol Sci. 2016; 58: 1-7.

[54] Olivier CE, Pinto DG, Teixeira APM, Santana JLS, Santos RAPG, Lima RPS. Immunoreactivity against Dermatophagoides pteronyssinus Assessed by the Leukocyte Adherence Inhibition Test in Patients with Intrinsic Atopic Dermatitis and Correlated "Intrinsic" Non-IgEmediated Allergic Conditions. European Journal of Clinical Medicine. 2021; $2: 45-50$.

[55] Dunn IS, Halliday WJ. Interactions between T and B lymphocytes and macrophages in the production of leukocyte adherence inhibition factor. Cellular Immunology. 1980; 52: 48-61.

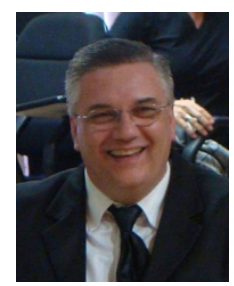

C. E. Olivier. Born in Brazil in 1963. Physician graduated from the Faculty of Medicine of the State University of Campinas (1986). Medical residency at the Faculty of Medicine of the State University of Campinas (1988). Specialist in Allergy and Immunology from the Brazilian Association of Allergy and Immunology (2011). Certified in the area of Pediatric Allergy and Immunology by the Brazilian Society of Pediatrics (2015). Specialist in Clinical Analysis by the Faculty of Health Sciences of the Methodist University of Piracicaba (2012). Doctorate (Ph.D.) in Clinical Medicine (under the guidance of Prof. Dr. Ricardo de Lima Zollner) concluded at the Department of Allergy and Immunology of the Faculty of Medicine of the State University of Campinas (2012).

$\mathrm{He}$ is the Senior Researcher of the Americana's Alergoimuno Institute (Instituto Alergoimuno de Americana). He has experience in the field of Medicine, with an emphasis on Allergy and Immunology and Clinical Analysis.

Dr. Olivier is a member of the Brazilian Association of Allergy and Immunopathology. ORCID: 0000-0001-7541-3182. His curriculum vitae can be accessed at http://lattes.cnpq.br/7035870789320492.

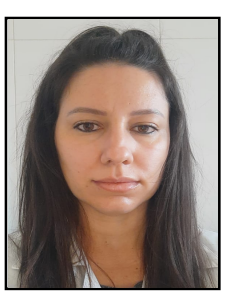

D. G. Pinto. Born in Brazil in 1985. Biomedic graduated from the Faculty of Americana (2010). She is a researcher in the Americana's Alergoimuno Institute (Instituto Alergoimuno de Americana). He has experience in the field of laboratory Medicine, acting mainly on the following themes: preparation of allergens and allergoids for in vivo, ex vivo, and in vitro diagnosis of allergy, leukocyte adherence inhibition tests, precipitins, and immunoblot.

ORCID: 0000-0002-4464-6669. Her curriculum vitae can be accessed at http://lattes.cnpq.br/6423437970305610.

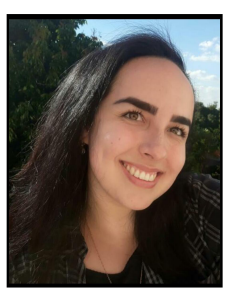

A. P. M. Teixeira Born in Brazil in 1996. Biomedic graduated from the Faculty of Americana (2018). Former trainee (2018) from the Americana's Alergoimuno Institute (Instituto Alergoimuno de Americana). He was trained in the field of laboratory Medicine, acting mainly on the following themes: preparation of allergens and allergoids for in vivo, ex vivo, and in vitro diagnosis of allergy, skin-allergic tests, leukocyte adherence inhibition tests, precipitins, and immunoblot. ORCID: 0000-0001-5140-9285

Her curriculum vitae can be accessed at http://lattes.cnpq.br/9364659098398568.

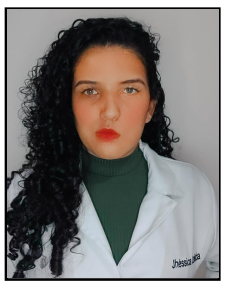

J. L. S. Santana. Born in Brazil in 1997. Biomedic graduated from the Faculty of Americana (2021).

Former trainee $(2020 / 2021)$ from the Americana's Alergoimuno Institute (Instituto Alergoimuno de Americana). He was trained in the field of laboratory Medicine, acting mainly on the following themes: preparation of allergens and allergoids for in vivo, ex vivo, and in vitro diagnosis of allergy, skin-allergic tests, leukocyte adherence inhibition tests, precipitins, and immunoblot. ORCID 000-0001-8519-127X.

Her curriculum vitae can be accessed at http://lattes.cnpq.br/4811507530904182.

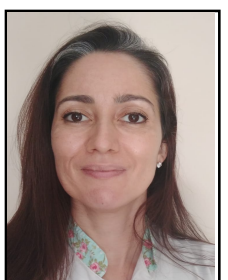

R. A. P. G. dos Santos. Born in Brazil in 1976. Nurse graduated from the Anhanguera Santa Barbara Faculty (2016).

She is a researcher in the Americana's Alergoimuno Institute (Instituto Alergoimuno de Americana). He has experience in the field of diagnostic Medicine, acting mainly on in vivo diagnosis of allergy. ORCID: 0000-0001-6469-8207.

Her curriculum vitae can be accessed at http://lattes.cnpq.br/2757001223214460.

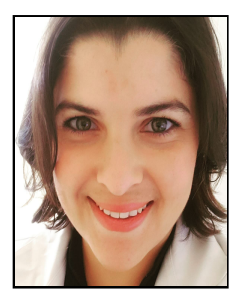

R. P. dos Santo Lima. Born in Brazil in 1985. Biomedic graduated from the Anhanguera Santa Barbara Faculty (2015).

She was a researcher in the Americana's Alergoimuno Institute (Instituto Alergoimuno de Americana). He has experience in the field of laboratory Medicine, acting mainly on the following themes: preparation of allergens and allergoids for in vivo, ex vivo, and in vitro diagnosis of allergy.

\section{ORCID: 0000-0003-4845-8822.}

Her curriculum vitae can be accessed at http://lattes.cnpq.br/2757001223214460. 